\title{
From the desk of FOGSI President 2018
}

\author{
Jaideep Malhotra ${ }^{1}$
}

Received: 27 February 2018/ Accepted: 27 February 2018/Published online: 29 March 2018

(C) Federation of Obstetric \& Gynecological Societies of India 2018

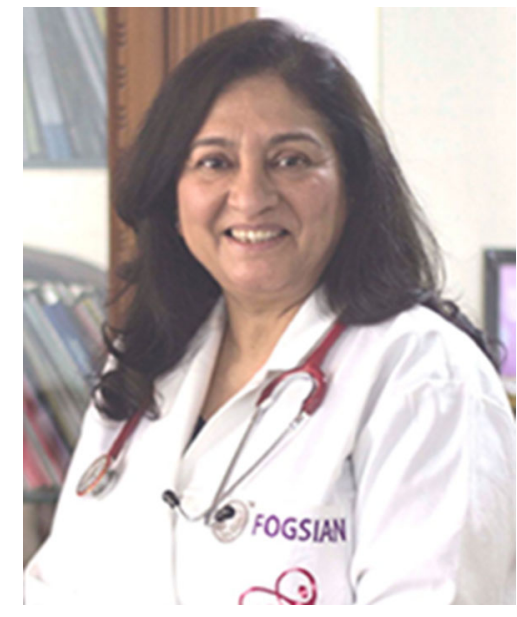

Our Honorable Chief Guest Shri Naveen Pattnaik, Guest of Honor Shri Pratap Jena, outgoing President of FOGSI-Dr Rishma Pai, Chairperson of the 61st AICOGDr PC Mahapatra, dignitaries on and off the dais, faculty and friends from all over the world, representatives of GoI, various NGOs, my mentors, respected seniors, dear colleagues and my valuable friends.

Feels like yesterday, when a newlywed young girl, filled with love in her heart, stars in her eyes and the desire to

Jaideep Malhotra

jaideepmalhotraagra@gmail.com

1 Agra, India achieve, stepped into a household with a legacy of dedicated Obstetricians and Gynecologists of over two generations. This was in the small, yet famous city of Agra holding hands of her man-her life partner!

In the first year itself, she was introduced to the word FOGSI and was taken to attend her very first FOGSI conference, the 28th AICOG at Durgapur in the year 1984 and met all the stalwarts of the organization then, who left a significant impact on her young impressionable mind.

Thereafter, she made numerous visits to the Taj Mahal, hosting dignitaries of Obstetrics and Gynecology from across the world, who wanted to visit the world famous monument. Little did she realize that the Taj Mahal is not just a monument of unmatched world class, impeccable architecture, but is also considered the ultimate reminder of the eternal love of the Mughal emperor-Shahjahan, for his wife Mumtaz Mahal. Alas, the magnificent Taj is also an iconic reminder of maternal mortality, which she will stand on this platform and address one day!

Dear Friends, I started this 33-year long journey, seeing FOGSI being shaped up by the respected stalwarts, and have been slowly climbing up the ladder without any intention or realization. The only intentions were to be engaged in service before self.

How time flew by, from a young FOGSIAN, finally to this very day, remains an enigma. All this would have simply not been possible without the immense love, affection and blessings of each one of my mentors, my teachers and my innumerable friends from India and across continents. 
I would take this opportunity to thank each one of you and few special mentors and friends from overseas who have inspired me a lot. One person who has really inspired, not just me, but thousands of Obstetricians and Gynecologists all over the world, with his very sharp analytical acumen and strict approach to streamlining a lot of work in FOGSI and now in FIGO - my very special salute to Prof. C. N. Purandare and family for always being there.

Last but not the least, my lovely family, right from my grandmother-in-law, to my in-laws, Dr RM Malhotra, late Dr Prabha Malhotra, my grandparents and parents who would not have ever dreamt that one day their little girl will climb many ladders and reach where few have made it. I am very thankful to almighty that one person, whom I love dearly and who has worked diligently in shaping my early years is here today watching it all. Thank you Bhuji Prof Tripat Kaur for always being a great motivator and a source of inspiration.

I thank God for blessing me with beautiful children Neharika, Keshav, Rishabh and granddaughter Neerali, who are the fourth generation of dedicated medical professionals in the Malhotra clan in service of humanity and in constant pursuit of excellence. My sisters, brothers-inlaw and cousins from America who are all present here in my moment of joy, I thank you all for your everlasting love, support and understanding through thick and thin.

Dear friends, people often remark that husband and wife should not be in the same arena of professional competence, lending itself to too much conflict and interference. But today, Narendra and I prove all of them wrong. We feel that it was the best decision of our lives. As we carry on complementing and supporting each other, this is our tribute to our mother's dreams that both of us today have created history in FOGSI to become the first couple to be Presidents of any professional organization of the world, and also both to be honored by the honorary FRCOG.

My heartiest congratulations to Dr Rishma Pai for a wonderful action-packed year 2017 with many new innovative ideas and activities, which have put FOGSI on a real pedestal among fellow organizations of the country. She has done commendable work and deserves a grand applause.

Dear Friends, a woman is omnipotent, and within her she has the power to create, to nurture and to transform. Given a chance, she would be strong enough to carry the whole world on her strong shoulders. But...she is always left struggling for her very existence right from conception.

My theme for the year is "Give HER wings and let her Soar."

I will be having a two pronged approach, one for HER (Health, Empowerment and Respect) for the women of our country, by my fraternity with QED (Quality, Ethics and
Dignity) and together we will work toward strengthening the doctor-patient relationship.

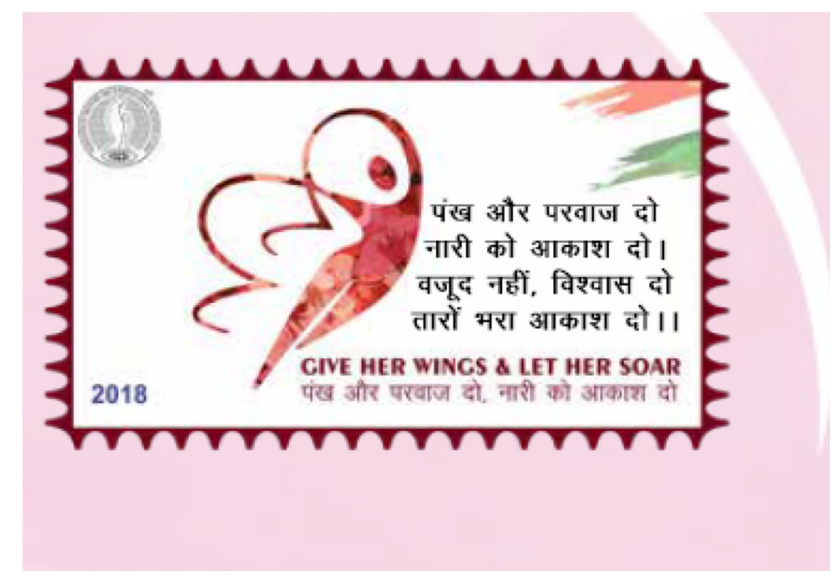

In this day and age when the economy is doing reasonably well, despite the exploding population, lack of infrastructure in healthcare and skewed doctor to patient ratio, there is an ever-rising expectation among our people. Our fraternity, in spite of dedicated and devoted service, appears to be at a receiving end from all sides. What has gone wrong in all these years? Once revered as Gods, now why have been reduced to becoming punching bags for all?

Look into our hearts; we die a thousand deaths every day. Everywhere we go people are looking at us, as if there are no bigger criminals. This is not what we are and the truth is that whole system cannot do without us. So a real introspection is required by each one involved, be it the people, policy makers, GoI, media, and us.

Clearly, there is a lot of apathy and lack of serious concern for women's lives in our country. We must strive to bring the maternal mortality rates down as much as possible and as soon as possible. If a mobile can reach in every nook and corner, then why can't medical aid and healthcare workers.

"We make a Living by what we get, but we make a

Life by what we give!"

—Winston Churchill

I salute to each and every one of you. Every single gynecologist sitting in the remotest corners of our country and serving our women, saving lives against all odds and facing all kinds of mental, physical, psychological, and financial torture. I can bet, nobody can be in your shoes for even an hour. Access to health care is one big lacuna in any healthcare system especially in the developing countries and the onus lies on the policy makers and not us. Health of an individual lies in his own hands and he has to seek, when and wherever required. If a man from a rustic village has to reach out to a distant relative, he/she will, by any 
means. But when it comes to health or safe delivery of their women, the onus lies on the doctor! Can anyone explain to me how? We need to understand these very critical issues and handle them with mindfulness. Once a patient is brought in late stages of a complicated health problem, there isn't much a doctor can do sitting in a PHC, CHC or a tertiary care. Still, they do whatever best can be done. However, who is at fault if the patient does not do well after coming to the hospital in late stages and if the patient does not have enough to pay for the healthcare services in private care? "Doshi Kaun?"(meaning, who is guilty?) is a film produced by Agra Obstetrics and Gynecological society, trying to inculcate in patients, the onus of responsibility toward their own health, which will be on website for all FOGSIANS to download and play in their clinics or similar places.

Today, I am going to address the major issues for which we Obstetricians and Gynecologists are at the receiving end. Very recently, some 1.3 lakh women signed a petition that their cesarean sections have been performed unnecessarily. On behalf of all of you, I disagree. Today the whole system is against the healthcare, have we sat down and analyzed, why the situation is what it is? There are very few Obstetricians and Gynecologists in the country, but there are even fewer paramedics ready to work efficiently. We often compare ourselves with Sri Lanka. Did anyone ask how they do it? Whether it is maternal, infant mortality or vaginal delivery rates. It is only because of trained dedicated paramedical staff, who diligently work hand in hand with their system and achieved the unachievable. 35,000 gynecologists in spite of their best efforts, cannot hold hands of 26 million delivering mothers. We should analyze, and make strategies which will assist our obstetricians to perform better in the most adverse circumstances. Thank you very much Shri J. P. Naddaji, Honorable Health Minister for whole heartedly supporting us and appreciating the contributions of FOGSIANS toward the health of our women.

We are going to take, our Honorable Prime Minister's brilliant futuristic initiative of PMSMA many steps further. We are launching "Adbhut Matrutva Initiative," tomorrow on 19th January 2018. This concept is based on the values of preconception counseling, recommended number of antenatal visits, promote institutional deliveries and top it up with early initiation of breast feeding, postpartum contraception and connect it with GOI "Indra Dhanush Program" for universal vaccination and immunization. FOGSI has liaisoned with Sister Shivani, and GOI and come out with a module which will not only look after various aspects of pregnancy and safer delivery, but also take care of fetal origin of adult diseases.
"Strive not to be a success, but rather to be of value." -Albert Einstein

Today India stands tall in the world on almost all fronts, thanks to the current leadership. For achieving this in a very short time, let us put our hands together and set an example for the health of our women too. I would appeal to our Prime Minister ji to link "Adbhut Matrutva" to "Skill India," "health for all" program.

Now coming to how we can achieve our goals for our dying mothers and neonates. Few steps that should be taken in the right direction by all stakeholders are as follows:

- Linking primary hospitals, to secondary to tertiary care hospitals.

- Having Mobikes and ambulances equipped with all EMOC tools and disposables.

- Training paramedical staff for monitoring of pregnancy and labor, enabling them to recognize the danger signals and early referral to a tertiary care.

- Strengthening our rural infrastructure and manpower.

- Integrating various agencies and NGOs to work in cohesion and synergies.

A burning painful area of concern, not from today, but for many decades is our dwindling female population. Only doctors cannot be accountable for the health of the nation. Each and every stakeholder including the administration and policy makers and the society must be made accountable. Holding us answerable and slamming rigorous punishments for clerical mistakes which are casual errors by the paramedics or support staff are not justifiable in any legal system. I must mention the efforts of the PCPNDT core committee headed by Dr Prakash Trivedi, Dr Jaydeep Tank, Dr Rajni Contractor and Dr HD Pai for challenging certain draconian sections of the act in the Honorable Supreme Court and I am pleased to announce that this writ petition has been admitted in the supreme court.

We are the best in the world. Asian doctors are highly respected, knowledgeable and in demand all over the world and many studies have proven them to be most hardworking in the world. How is it that these doctors who do so well in the west cannot perform as well or earn as well in their own countries? This needs serious introspection and understanding at all ends.

To make a larger and much faster impact on our healthcare outcomes, there is no other option except that government extends a helping hand to us. This should be in terms of upgrading the existing private medical facilities, easing out their stressors as far as licensing, certification, staffing, commercial taxes, and protection against unnecessary litigation and red-tapeism. When these 70 percent 
private healthcare professionals will receive apt motherly treatment, the results will be phenomenal. Nations' healthcare can improve, only by strengthening and supporting its healthcare providers. They need all the respect, dignity, love, and positive energy to work for their patients from both the government and the public.

One of our major problems is our population, ladies and gentlemen. We need serious brain storming and political will toward rationally addressing this.

Next is our education system. Our dealing with adolescents on the whole needs improvement. The emphasis on physical, mental and sexual health needs of the youth have to be addressed in school and colleges, and not when they are already under the sun. Our school and college teachers need to be trained to deal in these very sensitive areas and be involved with their students, not merely delivering the scheduled lectures.

Today, we only know statistics about maternal mortality, neonatal and infant mortality and maybe a few other diseases. Keeping this in mind, this year we have initiated a dedicated research group of about 150 FOGSIANs, starting work from tomorrow on more than 15 research projects and surveys. Thank you Dr Ben Mol and Dr Deepika Deka for coordinating this. FOGSI today feels very proud to offer a unique Hospital and Patient Management software with App to all its members totally free of cost, called the "DIGITAL FOGSI" initiative of FOGSI, again in line with our dear Prime Ministers' Digital India, Healthy India Initiative. If we adopt this, we will not only make our lives easier, but also a lot of data can be on the tips of our fingers and all registries will be much easier to work on.

Last year we initiated our first FOGSI chapter across continents-The London chapter, and this year I am happy to announce that we will be adding the Dubai chapter very soon and I am aware that many more are waiting too.

Dear FOGSIANS, your first health survey begins tomorrow morning at the SMRITI stall, please go and register your health parameters tomorrow itself, so that we can work out health strategies for you. In February, a very special event FOGSI for FRATERNITY conclave is being organized in the Holy city of Varanasi. I urge all of you to attend this in large numbers, where a lot of new ideas and schemes will be introduced.

FOGSI year 2018 is an action-packed year with every month dedicated to one issue or health problem. We will have five focused conferences by my Vice Presidents, "Surgical Rendezvous" at Dehradun by Dr Pratima Mittal, "Multiple Pregnancies and Medical disorders" at Ahmedabad by Dr MC Patel, "Art and Craft of Vaginal Delivery" at Udaipur by Dr Lila Vyas, "30 + Solutions at 30 +" at Vijaywada by Dr Jayam Kannan and "Preventive Oncology" at Gangtok by Dr Rajat Ray. Along with this, a "Breastcon" at Indore organized by Dr Kavita Bapat and team, "critical care" at Bengaluru by Dr Alpesh Gandhi and team, "Gestosis" at Nagpur by Dr Suchitra Pandit and team and "Women Health for Women Empowerment" by Dr Meera Agnihotri will be held.

A major INTERNATIONAL WOMEN'S HEALTH SUMMIT will be held in June in Delhi involving all stake holders, organizations, NGOs, Policy makers and GoI and a leadership summit for our very young FOGSIANS who are our future is being organized at Manesar in August. To sharpen our communication skills, FOGSI is joining hands with Communicon in March this year, organized by Dr SN Basu along with GOI.

365, that is almost one QED CME's or a workshop per day along with skill enhancing programs will be rolled out from 22nd of January itself.

Apart from our wonderful Journal, FOGSIANS will receive many communications from the President and office, Dil se Dil tak, TOG times, FOGSI connects, a weekly letter and innumerable messages via social media. Along with this Dr Firuza Parikh has generously made it possible to have access to "Fertility Sterility" journal for which a link will be provided to all. My special thanks to Mr JP Vij and Mr Venkat for all the timely help and support promised for our publications.

Our Indian college has been doing phenomenal work. Apart from smoothly running so many certificate courses, ICOG hour in all Yuva conferences, Dr CL Jhaveri Symposium in AICOG, and PG Force program in all medical colleges along with our CME committee this year, the ICOG will also be organizing the "Principles, practices and protocols" conference under the leadership of Dr Shantha Kumari at Hyderabad.

FOGSI along with ICOG framed the National Nutritional consensus during my tenure in ICOG, and today we are launching the National Nutrition Registry as the first of its kind comprehensive national repository of nutritional status of women of India. We are going to hold camps "Pan India" collecting data on the nutritional status of Indian women by a unique App created for the purpose christened "Nutrimeter."

27 chairpersons of our committees and 25 governing council members of ICOG is a formidable taskforce. They are working on making of protocols, algorithms, patient education pamphlets, FOGSI Focuses, E-connects, modules for CMEs and surveys, and public awareness and international academic exchange.

To the GOI,

"I can conquer the world with one hand as long as you are holding the other."

- Megan Smith 
FOGSI pledges to further all projects of GOI and roll them out to its members to join hands for faster and farther access, I thank the Honorable health minister Shri JP Naddaji, Ms Anupriya Patel, all health secretaries right from Shri Manoj Jhalani, Dr Vandana Gurnani, Dr Sikdar, Dr Dinesh Banswal, Dr Sumita Ghosh for fruitful FOGSI involvements.

No one-and I mean it-no one, can do it all or achieve it all. Teamwork is the spirit, whether it is between you and me, or between associations, or public private partnership. Being a team player is the key essence. Therefore, this year we are taking up many liaising activities.

- FIGO and FOGSI on Fertility tool box, GDM, hypothyroidism and environmental health.

- IMA and FOGSI are going to liaise for noncommunicable diseases.

- AOFOG and FOGSI on reducing the 5Ps.

- SAFOMS, IMS and FOGSI are going to do joint CMEs on "Fit at forty, strong at sixty and independent at eighty."

- SAFOG and FOGSI on reducing maternal mortality.

- RCOG and FOGSI on trainings and guidelines.

- RCPI and FOGSI on systems and education.

- Ian Donald and FOGSI for ultrasound updates. Thanks to Prof Asim Kurjak, Frank Chernavak, Prof Narendra Malhotra, and Shiv and Raj Menon.

- In August Skill Enhancement and Leadership Program for Yuva with HELM (Health Economics, Transformational, Leadership and Collaborative Management).

- Global hysteroscopy group for hysteroscopy skills, Prof Sergio Hamovich is here today to show his commitments.

- CEMAST and FOGSI on hands on skill training.

- IPAS and FOGSI for safe abortion.

- IAP for newborn resuscitation workshops.

- ISPAT and FOGSI will do six CMEs on Nutrition, four global webinars called "E connect 2 on nutritional supplementation."

- All the NGOs on save the girl child specially Smriti, Beti bachao beti padao, menstrual hygiene, contraception.

- Special thanks to Dr Hema Divakar and Mrs Pompy Sridhar and team Merck for mothers and Dr Bulbul Sood and team JHPEIGO for Manyata project.

- Global strategies for helping streamline many issues regarding MTP. Thanks to Mrs Sushma Kapoor \& Anjali Nayyar.

- She decides, thank you Robin Gorna for bumping into me in the lift, we might be starting a revolution.

- Hep B vaccination at discounted rates for all the medical and paramedical staff of FOGSI members.
We are here with open arms ready to liaise with likeminded and sensitive organizations for women's health and education.

This year we have come out with exclusive branding merchandise for FOGSI and I would request all FOGSIANS to do it with utmost pride. We are proud of our organization.

To all the pharma industry friends, I have no words to thank you for your blanket support for all academic and CSR activities, I feel truly blessed with your association and faith in me and FOGSI.

A big big thank you from the bottom of my heart to Dr PC Mahapatra and Hara Pattnaik and team AOGO, we have done it against all odds and challenges. God bless you.

Thank you to my team backhome.

I leave myself and my fraternity with the continued sentiment of-Giving!

"It is the Generous Giving of Ourselves that produces the Generous Harvest!"

I wish you all a very, very happy, healthy, and prosperous New year, may 2018 bring smiles on the faces of our patients and may there be no preventable maternal deaths and may all of us restore the trust and relationship we have been sharing with our patients.

GOD BLESS FOGSI

GOD BLESS INDIA

VANDE MATARUM

JAI HIND

Prof. Dr. Jaideep Malhotra

MD FICOG FICMCH FICS FMAS FRCOG FRCPI

FOGSI PRESIDENT 2018

आसमा की ऊचाई है मंज़िल मेरी, तारों की गहराई है चाहत मेरी, मेरी आवाज की बुलंदी को सुन, मेरी परवाज़ की लरज़िश को समझ,

मैं एक कमसिन, कमज़ोर काया नही हूँ, किसी के ख्वाब की माया नहीं हूँ, मेरी हिम्मत, मेरे जज़्बात में है, मेरी ताकत मेरी आँचल में है,

मुझो उदासिन न परख,

मैं जितनी बाहर हूँ.

उस से कंही अधिक भीतर हूँ मैं हूँ. आज की नारी, आज की शक्ति. 